\title{
LA FALTA GRAVE LABORAL
}

Mario Pasco Cosmópolis

La falta grave laboral es tema importante del Derecho del Trabajo, pues aquélla constituye en casi todos los países la causa unánimemente aceptada por la terminación justificada del contrato de trabajo. Conceptualmente -en tanto incumplimiento contractual-, puede ser cometida por el trabajador como por el empleador, y autorizar a la contraparte a dar por concluido el vínculo. En su acepción más generalizada, empero, está referida a la conducta del trabajador y es, por lo tanto, el principal de los motivos para legitimar la más radical de las sanciones: el despido disciplinario.

El tema asume caracteres aún más trascendentes en los países como el nuestro donde existe estabilidad absoluta en el empleo, derecho que hace prevalecer la subsistencia del vínculo laboral sobre la voluntad del empleador y que somete la ruptura del mismo a la existencia de una causa justificada, causa que algunas veces es sólo la falta grave en el ámbito individual.

\section{Definición}

La falta grave puede ser definida como el incumplimiento contractual imputable al trabajador, a tal punto grave que no permite la continuación de la relación laboral; esto es, una lesión irreversible al vínculo laboral, producida por acto doloso o culposo del trabajador, que hace imposible o indeseable la subsistencia de la relación laboral y que autoriza al empleador a darle término sin necesidad de preaviso ni obligación de pago de indemnización por despido.

Américo PLA RODRIGUEZ la define como "conducta insoportable que hace imposible la continuación del vínculo laboral" (1); Carlos CARRO ZUÑ IGA, como "incumplimiento contractual,

(1) En Fórum realizado en Lima por la Asociación Peruana de Relaciones de Trabajo, en noviembre de 1982 . 
culpable y GRAVE del trabajador" (2) que es la fórmula del art. 54.1 del Estatuto de los Trabajadores de España; el D.L. 22126 peruano lo hace, de modo elíptico, en su art. $1^{\circ}$ : "Casos en que, por acción u omisión, el trabajador incumple sus obligaciones en perjuicio de la producción, la productividad, la disciplina y armonía en el centro de trabajo".

Todas las definiciones giran en torno a un concepto uniforme y claro: "Notoria mala conducta que justifica el despido". En cuanto hecho es, pues, una infracción dolosa o de insalvable culpa que se produce en agravio de la empresa, de sus representantes o de la producción, y se la denomina también "injuria laboral", "mala conducta" o "inconducta".

Que sea grave es requisito sine qua non: Las faltas menores son sancionables, dentro de la órbita de las facultades disciplinarias del empleador, con amonestación verbal o escrita o con suspensión sin goce de haber por uno o más días.

La gravedad de la falta deviene por lo general de la naturaleza intrínseca del hecho, aunque a veces deriva de su reiteración, lo que hace que la aplicación de la sanción deba ejecutarse sobre la base de la evaluación de la infracción cometida y de los antecedentes del sujeto. Sin embargo, estos antecedentes en el caso laboral sólo tienen valor cuando corresponden al mismo ilícito; por ejemplo, en las ausencias consecutivas que constituyen abandono del trabajo o las discontinuas que se acumulan; en el desacato, tipificado como la reiterada resistencia al cumplimiento de las órdenes; en la embriaguez, que debe también ser habitual o, al menos, repetida.

No se agrava la falta por los antecedentes disciplinarios en casos diversos al que se pretende sancionar con el despido. En sentido estricto, tales antecedentes sólo operan subjetivamente para orientar la decisión de despedir, pero no objetivamente para valorar la falta; aunque como dice Alfredo J. RUPRECHT (3): "Hay

(2) "La falta grave como causa de despido", en El Derecho Laboral en Iberoamérica, México, 1981, p. 299.

(3) “Contrato de Trabajo", Buenos Aires, 1960, p. 407. 
que tener un criterio cuantitativo y cualitativo. Una falta leve, reiterada, puede llegar a ser grave (cuantitativo); una falta seria puede perder ese carácter por haber sido cometida por un trabajador intachable, con muchos años de servicios (cualitativo)".

\section{Caracteres}

Los caracteres de la falta grave, esto es, los requisitos para que una infracción laboral configure causa justificada de despido, son precisados de manera diversa por los autores.

Wagner GIGLIO (4) señala que para DORVAL DE LACERDA serían siete: previsión legal, perjuicio al denunciante, veracidad, actualidad, gravedad, vínculo etiológico y conexión con el servicio; para Mozart Víctor RUSSOMANO, tres: gravedad, actualidad e inmediación entre la falta y la rescición; y para la mayoría de los autores: gravedad, actualidad y relación causa-efecto (nexo etiológico).

Para Manuel ALONSO OLEA son también tres: el incumplimiento del trabajador debe ser contractual, grave y culpable (5).

Para GIGLIO, "la gravedad es el único requisito; todos los demás son factores externos; importantes, pero extraños a la infracción en sí misma". Desarrollando esta idea, cita a BORTOLOTTO en la definición del criterio de evaluación de la gravedad: "Sólo habrá acto faltoso suficiente para justificar el despido cuando se verifica una infracción, de tal modo grave, que impida la continuación, incluso provisional, de la relación de trabajo" (6), que es prácticamente la definición de la ley italiana (art. 2.119, párrafo $1^{\circ}$, del Código Civil).

La gravedad es consustancial al concepto; el adjetivo se enlaza de modo tan inseparable al sustantivo que, en realidad, forman un solo vocablo, una palabra compuesta: "falta-grave"

Como dice CARRO ZUÑIGA, "la causa de despido, en tanto

(4) “Justa causa”, Sao Paulo, 1981, p. 21.

(5) “Derecho del Trabajo", Madrid, 1980, p. 300.

(6) Op. cit., p. 23. 
"justa", debe ser de entidad notable y suficiente, capaz de generar en equitativo equilibrio y correspondencia, el serio acto potestativo de desvinculación unilateral del empleador" (7).

No es, sin embargo, la gravedad el único requisito, en nuestra opinión. También lo es la tipicidad, en particular en los países que han adoptado el sistema cerrado o de "numerus clausus" en su calificación. Si una infracción, aún manifiestamente "importante, intensa o grande", no está expresamente señalada en la ley, siendo falta y siendo grave, no es "falta-grave" en el estricto sentido jurídico que a este término se le asigna, como motivo justificado de terminación de la relación contractual.

La hipótesis no es arbitraria, ni un mero ejercicio especulativo, sino que ha tenido y siempre puede tener concreción real. Es el caso auténtico del Decreto Ley 18471 peruano que omitió señalar como faltas graves el faltamiento de respeto, la agresión física (lo que permitió la reposición en el trabajo de personas que, por ejemplo, habían golpeado físicamente a sus superiores jerárquicos) y el sabotaje; y es también el de algunas faltas omitidas por el actual Decreto Ley 22126, que veremos más adelante.

Cabe siempre, por cierto, aducir que una infracción como el sabotaje importa una inexcusable violación de los deberes fundamentales que emergen y dan sustento a la relación laboral. Pero por este tipo de razonamiento, no existiría jamás una tipificación taxativa pues todo acto infractorio, de acuerdo a la perspectiva de quien lo juzgue, podría quedar incorporado en el concepto de falta grave.

Tipicidad y gravedad son, entonces, a nuestro criterio, los caracteres o requisitos esenciales para que una infracción laboral sea admitida como suficiente para justificar el despido disciplinario.

Hay, no obstante, principios que contornan a la falta grave y que condicionan su aplicabilidad. Tales principios, que configuran el marco jurídico en que se desenvuelve la facultad sancionado-

(7) Op. cit., p. 299. 
ra del empleador, tienen especial relieve cuando se trata de la falta grave, que es el mayor de los ilícitos laborales, y del despido, que es su máxima sanción.

Sucintamente pueden ser enunciados como:

- Inmediación: La falta debe ser sancionada tan pronto es advertida o, en caso sea necesario, al culminar la investigación que la demuestra. La falta no sancionada oportunamente se reputa condonada.

GIGLIO opina al respecto que "no bien tome conocimiento de la práctica de un "acto faltoso", el empleador debe proceder a la aplicación de la penalidad. No haciéndolo, el empleador mantendrá, por así decirlo, engatillada y apuntada contra el empleado el arma de que dispone: el poder de sancionar; viviendo sobre permanente amenaza de ser sancionado, el empleado no tendría libertad para manifestar su voluntad, transformándose en un semi-incapaz" (8).

Añade, sin embargo, al respecto:

"En caso de justa causa configurada por una serie de "actos faltosos" sucesivos en el tiempo, pero reiteradamente practicados (desidia, práctica de juegos de azar, etc.), la actualidad de la falta será considerada a partir del conocimiento de la última infracción"' (9).

- Demostración: Aunque hay legislaciones que condicionan el despido a la realización previa de una investigación exhaustiva, es decir, que lo colocan como la culminación y no en el inicio de un proceso, lo más corriente es que la facultad de despedir sea ejercida unilateral y discrecionalmente por el empleador.

La exigencia de demostración de la veracidad de la acusación es posterior, y ocurre a consecuencia del reclamo que el servidor afectado pudiera hacer ante los órganos jurisdiccionales.

(8) Op. cit., p. 24

(9) Ibid, p. 28. 
- Imputación: El despido es acto unilateral pero necesariamente recepticio. Es requisito para su validez el que la falta haya sido comunicada al trabajador; que éste sea emplazado con una acusación clara, directa, precisa, inequívoca.

Ello, en primer lugar, para permitir su adecuada defensa; pero, además, porque la falta no sancionada queda perdonada. No es válido argumentar en juicio, como justificación del despido, una infracción que no fué invocada expresamente en el documento formal en que la sanción fué puesta en conocimiento del trabajador.

\section{- Non bis in idem}

Otro principio fundamental que entorna necesariamente la sanción consiste en que al empleador "no le es permitido renovar la punición, por la misma falta. Su derecho de sancionar se agota con la aplicación de la penalidad escogida. En caso contrario, esto es, si fuese posible reconsiderar la penalidad para agravarla o repetirla, caeria por tierra toda la estabilidad de las relaciones laborales, toda vez que el empleador gozaría de un poder dictatorial, manteniendo a sus empleados en una permanente y angustiosa incertidumbre, amenazando constantemente con una repetición de la pena, en el momento que mejor le aprovechare" (10).

En cuanto a otros factores mencionados por diversos autores tales como vínculo etiológico, conexión con el servicio, perjuicio al empleador, entendemos que ello aparece involucrado en el concepto de tipicidad: la ley sólo admite como falta grave aquélla infracción que reúne tales características. Diversamente, si teniéndolas, la ley no la reconoce como tal, carece de la base jurídica indispensable para ser reputada falta grave.

\section{Tipificación}

Los sistemas usados para identificar la falta grave son: a) tipificación legal; b) tipificación jurisprudencial; y, c) mixto; a los que José MONTENEGRO BACA (11) denomina respectivamente:

(10) Ibíd., p. 22

(11) En el Fórum de APERT (Lima, noviembre de 1982). 
a) enumerativo o taxativo; b) abierto; y, c) enumerativo-ejemplificativo; y le agrega un cuarto, al que denomina" convencional".

a) Tipicidad legal: Se basa en el principio penal "nullum crime sine lege" y corresponde a lo que algunos autores llaman "sistema taxativo", de "numerus clausus" o de "ejemplificación cerrada"; "Falta es lo que está escrito en la ley".

El sistema es rígido y riesgoso, por la imposibilidad de prever todos los casos de probable infracción laboral y el peligro siempre latente de omisión en toda enumeración limitativa. Al decir de PLA. (12), "del mismo modo que no hay un código penal laboral que enumere todas las conductas castigables y establezca la sanción que corresponda a cada una de ellas, tampoco hay un catálogo de actitudes que merezcan el calificativo de notoria mala conducta. A veces puede estar constituido por un hecho de suficiente cantidad como para merecer por sí solo ese calificativo. Otras veces se requiere la configuración de una serie de hechos que merezcan, en conjunto, esa apreciación. Incluso en aquellos establecimientos donde haya reglamentos internos, las normas son lo suficientemente amplias y elásticas como para comprender un ancho margen en el cual se mueve la apreciación individual".

b) Tipificación jurisprudencial, llamado por algunos "sistema de numerus apertus", se basa en una definición muy amplia, genérica, conceptual - una cualquiera de las definiciones propuestas a lo largo de este trabajo o señaladas en las diversas legislaciones-, siendo el juez el que interpreta cada caso, lo aprecia en conciencia y lo decide.

La acumulación constante de casos similares crea corrientes decisorias que se erigen en pauta jurisprudencial.

Como sistema es flexible, muy apto para adecuarse a las cambiantes necesidades sociales; salva los inconvenientes de la enumeración exhaustiva y prolija.

Pero el legislador abdica en favor del Juez, al que se otorga

(12) "Los Principios del Derecho del Trahajo", Buenos Aires, 1978, p. 299. 
excesivo poder discrecional, por lo que conviene más a un esquema de "common law" que al legalista.

c) Mix to: Tipicidad legal suficiente y un cierto margen de interpretación jurisprudencial, capaz de ampliar la cantidad y calidad de las faltas. De "enumeración referencial" denomina a este sistema ROMERO; "adexemplum o enunciativo" CARRO ZUÑIGA.

Modelo de este sistema sería, precisamente, el Código de Costa Rica, que enumera taxativamente once faltas, pero en un último inciso agrega "cualquier otra falta grave a las obligaciones que impone el contrato", abriendo así margen a la tipificación por vía jurisprudencial.

Este también sería el sistema peruano según MONTENEGRO, para quien las faltas contempladas en la ley vigente son muy genéricas; son grupos de enunciados en que hay más causas que faltas. Así, por ejemplo, en el inc. a) del art. $4^{\circ}$ del D.L. 22126 , el incumplimiento de las obligaciones laborales es casi una definición global que corresponde a todas las causales, que cobija a todas las demás faltas, puesto que todas ellas son, en el fondo, un incumplimiento de obligaciones laborales esenciales.

No comparto esta opinión. El sistema peruano es de enumeración tasada o cerrada, pues en la ley hay algo de generalidad pero mucho de precisión, como sucede frecuentemente con la ley penal. La ley peruana no define en abstracto el concepto de justa causa o el de falta grave; no abre la enunciación con una fórmula como la costarricense; no otorga facultad extensiva al Juez. Es más: La Constitución se refiere textualmente a "justa causa, señalada en la ley", y eso cierra el debate.

d) En cuanto a la "tipificación convencional", bastante infrecuente, aparece por ejemplo en el numeral 6 del artículo $63^{\circ}$ del Código Sustantivo de Trabajo de Colombia, que permite considerar como falta cualquier violación grave calificada como tal en pactos o conven ciones colectivas.

\section{Sistematización}

No concuerdan las legislaciones en la tipificación de las faltas 
graves, ni aún aquellas que han adoptado el sistema cerrado o el enunciativo, pero hay evidentes analogías sustantivas que permiten ciertos criterios de clasificación u homogenización.

ALONSO OLEA (13), con referencia al Estatuto de los Trabajadores español, distingue: 1$)$ Defectos en cuanto a la prestación básica (disminución contínua y voluntaria en el rendimiento del trabajo normal o pactado); 2) Defectos de disciplina (indisciplina o desobediencia en el trabajador); 3) Defectos de conducta de carácter general (trasgresión de la buena fé contractual y abuso de confianza, ofensas verbales o físicas al empresario o a las personas que trabajan en la empresa o a los familiares que convivan con ellos); y de carácter especial (embriaguez habitual o toxicomanía).

Manuel ALONSO GARCIA (14), aunque referidas a la legislación española anterior, las clasifica en: 1) Incumplimiento (faltas de puntualidad y asistencia; disminución de rendimiento); 2) Insubordinación (indisciplina o desobediencia, malos tratos, faltas de respeto); 3) Infidelidad (fraude, deslealtad y abuso de confianza, concurrencia desleai); 4) Mala conducta (embriaguez habitual, falta de aseo, riñas y pendencias).

Francisco DE FERRARI (15), analizando la notoria mala conducta a que alude la ley uruguaya, considera que los quebrantamientos pueden afectar: 1) A las obligaciones que ha asumido el trabajador al ajustar el contrato.- 2) A la puntualidad y asistencia.- 3) A la diligencia y contracción al trabajo.-4) A otros factores tales como el daño causado intencionalmente a los bienes, la negligencia grave y la inobservancia flagrante de las reglas establecidas por la técnica, las costumbres o la disciplina de la empresa.

RUPRECHT considera las siguientes: 1) Incumplimiento de la obligación contractual (abandono del cargo, abandono del empleo, aseo, cancelación de la licencia profesional, daños, desobediencia, disminución del rendimiento, huelga, impuntualidad, inasistencias, indisciplina, incapacidad o ineptitud, injuria, insubordinación, mala conducta, negligencia, prisión o condena criminal, riña, viola-

(13) Op. cit. 302 y ss.

(14) "Curso de Derecho del Trabajo", Madrid, 1971, pp. 584-585.

(15) "Derecho del Trabajo", Buenos Aires, 1962, Tomo II, p. 516 y ss. 
ción del reglamento interno).- 2) Atentatorias a la fidelidad (delitos, divulgación de secretos, falta de confianza, negociación indebida).- 3) Motivos extracontractuales (agremiación, conducta privada, embargo, embriaguez, maternidad, matrimonio, personal en condiciones de jubilarse, proselitismo político o gremial) (16).

PEREZ LEÑERO (17) las clasifica en: 1) Causas económicas (inasistencia, impuntualidad, indisciplina, ineptitud, disminución del rendimiento).- 2) Causas morales-profesionales (fraude, concurrencia desleal).- 3) Causas morales-individuales (malos tratos, riñas y pendencias, embriaguez, falta de aseo).

Jorge Enrique MARC (18) las divide en: 1) Faltas de disciplina, distinguiendo entre la indisciplina propiamente dicha y la insubordinación.- 2) Contra los deberes de producción.- 3) Contra la administración (mal desempeño, incumplimiento de las disposiciones o reglamento).

Lupo HERNANDEZ RUEDA (19), no obstante que el Código de Trabajo dominicano contiene 21 faltas específicas y una genérica, en apreciable síntesis las clasifica en: 1) Inasistencia al trabajo.- 2) Faltas de diligencia.- 3) Desobediencia al patrono.- 4) Falta de fidelidad, competencia desleal y falta de probidaci u honradez.- 5) Injurias y malos tratos.- 6) Actos o intentos de violencia.

En sistema cerrado, la ley peruana no clasifica las faltas, como no lo hacen tampoco la Consolidación brasileña, que consigna 12 faltas especificas y una causa adicional de despido (atentado contra la seguridad nacional), ni el Código boliviano: 9 faltas (algunas de las cuales han sido afectadas por leyes posteriores).

Dentro del sistema abierto el Código colombiano señala 15 faltas específicas, el costarricense 11 , y el ya mencionado domini-

(16) Op. cit., p. 412.

(17) Cit. por RUPRECHT, Op. cit., p. 379.

(18) La facultad de dirección en la L.C.T. en "Temas de Derecho del Trabajo y de la seguridad social", Tucumán, 1982,p. 318.

(19) "Manual de Derecho Dominicano del Trabajo", Santo Domingo, 1976. p. 706 y ss. 
cano 21 faltas, a las que añaden una falta genérica que permite ampliar la tipificación por vía jurisprudencial o convencional.

\section{Falta Grave y Justa Causa}

"La locución "justa causa de despido" -dice MONTENEGRO BACA (20)- no es sinónimo de la frase "during good behaviors" (mientras dure el buen comportamiento), usada por los norteamericanos, porque la estabilidad puede terminar no sólo por el mal comportamiento del trabajador, sino también por causales ajenas a la buena o mala conducta del laborante, como, por ejemplo, auténticas causas de fuerza mayor que obliguen a cerrar el establecimiento o a limitar sus actividades".

En similar sentido, CABANELLAS refuta la identificación entre justa causa y falta grave. "Podría hablarse - dice-también de motivo legitimo, motivo imputable, causa legitima, causa imputable. A nuestro juicio no existe tal sinonimia; ya que el patrono puede tener justa causa para despedir al trabajador, una fuerza mayor que no sea la causa imputable a éste; puede igualmente el motivo ser legítimo y no existir falta grave". (21).

Falta grave y causa justa de despido no son, entonces, términos idénticos ni intercambiables. Causa justa es un concepto mucho más amplio y comorensivo; es género, mientras la falta grave es especie: Toda falta grave es causa justificada, pero no toda causa justificada es falta grave; o, dicho de otro modo, hay causas justificadas para la terminación del contrato por iniciativa o decisión del patrono que no constituyen falta grave.

No nos estamos refiriendo únicamente a las causales de ámbito colectivo, impersonales, no individualizables, como son la fuerza mayor, el caso fortuito, la situación económica de la empresa o el cambio tecnológico, sino a situaciones individuales, personales que también justifican esa terminación sin ser, necesariamente, un ilícito jurídico o ético.

(20) "La estabilidad en el empleo", en "El Derecho Laboral en Iberoamérica”, México, 1981, p. 321.

(21) "Contrato de trabajo", Buenos Aires, 1964, Vol. III, p. 307. 
a) ¿Causa justa, justa causa o causa justificada?

La doctrina usa frecuentemente la expresión "justa causa"; la Constitución Política del Perú, "causa justa"; el reciente Convenio $158^{\circ}$ de la OIT, "causa justificada".

Hay aquí un problema semántico más que jurídico. Pero lo semántico influye, por lo general, en lo jurídico. Como dice Efrén BORRAJO (22) "las cuestiones terminológicas tienen suma importancia al comportar siempre implicaciones conceptuales y no deja de ser lícito requerir del legislador se someta a una construcción técnica, en la que las palabras y las instituciones tengan un sentido univoco y constante".

Diferenciar entre "justa causa" y "causa justificada" no es sólo una sutiliza de un jurista tan refinado como Emilio MORGADO (23) sino que tiene antecedentes en la doctrina y la legislación comparada. GIGLIO (24) señala que "causa justa" es un concepto genérico que debe entenderse como todo motivo válido que autorice a la terminación de la relación de trabajo, mientras que "justa causa" sería sinónimo de falta grave. Como sucede en la legislación italiana, en la que es definida como "causa que no consiente la continuación, ni siquiera provisional, de la relación" (art. 2.119. párrafo $1^{\circ}$ del Código Civil).

Ello es explicable, sin embargo, en razón de existir otras causales que permiten la rescición del contrato; tales son los llamados "motivos justos", definidos como "notable incumplimiento de las obligaciones contractuales del trabajador o razones inherentes a la actividad productiva, a la organización del trabajo y al funcionamiento regular de la misma" (art. $3^{\circ}$ de la Ley 604 de 15.7.66 italiana).

Comentando estas normas, Juan Antonio SAGARDOY dice: "El motivo justificado, aún cuando encierra analogías con la justa

(22) Cit. por Dario HERNANDEZ MARTIN: "Negociaciones prohibidas", en Dieciséis lecciones sobre causas de despido, Madrid, 1969, p. 185.

(23) En el Fórum APRT de Lima (noviembre de 1983).

(24) Op. ct., p. 48. 
causa (una y otra se refieren a hechos imputables al trabajador), se separa necesariamente de ésta, asumiendo perfiles y rasgos propios. La diferencia esencial... consiste en la menor gravedad del "notable incumplimiento constitutivo del motivo justificado en sentido subjetivo. Mientras la justa causa entraña un hecho que hace imposible la continuidad, incluso provisional, de la relación laboral. en el motivo justificado el acto imputable al trabajador, a pesar de ser notable, permite que el contrato continúe hasta el vencimiento del término del preaviso" (25).

La legislación de los diversos países es pródiga en la conceptuación y denominación de las causas válidas para el despido. Así, el Código Civil alemán habla de "motivo grave y decisivo" (art. $626^{\circ}$ del BGB); la ley belga, de "motivo grave" (art. $35^{\circ}$ de la Ley de 3.7.78 relativa a los contratos de trabajo); el Estatuto de los Trabajadores uspañol, de "incumplimiento grave y culpable del trabajador" (art. 52\%); el Código de Trabajo francés, de "causa real y seria" (art. 122-14-3); el Código Civil holandés, de "motivo urgente" (art. 1.639); la ley sueca, de "justificación objetiva" (art. $7^{\circ}$ de la Ley $\mathrm{N}^{\mathrm{o}} 12$ de 9.1.74, sobre protección del empleo); y el Código Suizo de las obligaciones, de "motivos justificados" (art. 337.2).

En América, la Ley de Contrato de Trabajo argentina habla de "incumplimiento que configure injuria" (art. $242^{\circ}$ ); la Consolidación de las Leyes de Trabajo brasileña, de "justa causa" (art. $482^{\circ}$ ), al igual que el Código de Trabajo de Costa Rica (art. $81^{\circ}$ ) y el de República Dominicana (art. $77^{\circ}$ ); la Ley sobre Contrato de Trabajo de Chile, D.L. 2.200, de "causa justificada de caducidad" (arts. $14^{\circ}$ y $15^{\circ}$ ); el Código de Trabajo de Honduras, de "causas justas" (art. $112^{\circ}$ ); la Ley Federal de Trabajo Mexicana, de "causa justificada", (art. 460); la ley uruguaya (ley 14.489 de 1944, art. $\left.4^{\circ}\right)$ de "notoria mala conducta", igual que la ley venezolana contra despidos injustificados.

Como se ve, algunas leyes aluden a conceptos muy genéricos (motivo grave, causa justificada); otras, a conceptos más específi$\cos$ (injuria laboral, notoria mala conducta). Unas y otras, sin embargo y más allá de la nomenclatura, reconocen en la falta grave

(25) "La terminación del contrato de trabajo", Madrid, 1980, p. 88. 
el motivo más justificado, no el único pero sí el principal, para la terminación de la relación laboral por vía del despido punitivo.

Interesante es por ello la definición que muchas de esas leyes dan a la causa legal reconocida para generar tal efecto: E1 "motivo grave" de la ley belga es señalado como "toda falta grave que haga inmediata y definitivamente imposible la colaboración entre el empresario y el trabajador"; el "motivo urgente" holandés, como "actos, actitudes o comportamientos del trabajador que impliquen el que no se pueda pedir razonablemente al empresario la continuación de la relación laboral"; y el "incumplimiento que configure injuria" argentino, como aquél que "por su gravedad no consienta la prosecución de la relación".

Grave, urgente, serio, decisivo debe ser siempr: el motivo para ser suficiente a efectos de la terminación del vínc lo laboral. En tal perspectiva, "causa justa", "justa causa" y "causa justificada" resultan términos básicamente similares.

Toda ley tiene, en efecto, vocación, una aspiración esencial de justicia; apunta a ella; en ella se sustenta y afirma. Ley injusta, desde una perspectiva ortodoxa, constituiría una insalvable contradicción.

La justicia legal de que habla Tomás de Aquino se expresa, según palabras de Francisco Suárez (1548-1617), en la justicia como requisito intrínseco, esto es, esencialmente debido de la ley (26).

Lo aparentemente injusto desde una perspectiva individual puede ser justo en una perspectiva social. No son valores absolutos sino que refieren a la equidad entendida como la justicia -valor abstracto e inmanente - aplicada al caso o hecho concreto. Justo es, entonces, lo que la ley así declara, lo que la ley reconoce como tal. Ello, por cierto, desde un ángulo ideal al que no se le oculta la realidad fáctica de leyes injustas.

Dentro de un cuadro razonable debemos asumir como justo

(26) Ver Luis RECANSENS SICHES: “Filosofía del Derecho", México, 1961, pp. 484-485. 
aquello que una ley socialmente equilibrada justifica. Justo y justificado guardarían entre sí la misma relación que legítimo y legitimado: siendo términos distintos, surten los mismos efectos, operan como sinónimos.

\section{b) La justa causa de despido}

Clasificando los motivos justificados del despido, PLA RODRIGUEZ (27) señala que existen tres tipos de razones: a) las relacionadas con la conducta del trabajador; b) las relacionadas con la persona del trabajador; c) las relacionadas con la empresa. Respecto de las primeras precisa que "alcanzan exclusivamente a los trabajadores que hayan incurrido en un comportamiento incorrecto. En cambio, los motivos relacionados con las empresas pueden afectar jurídicamente a todos -o casi todos- los integrantes del personal".

A grandes rasgos, las causas pueden ser individuales o colectivas. Estas últimas, vinculadas a la realidad o situación de la empresa, suelen ser económicas, técnicas, caso fortuito o fuerza mayor, y. más que a un despido, autorizan a solicitar o negociar la terminación de los contratos. Son causas impersonales, generales, no individualizables por lo común; no conllevan nada denigrante para el trabajador ni se originan en una inconducta. Son situaciones ajenas a la voluntad de ambas partes que no conducen a la terminación del contrato laboral por decisión unilateral del patrono sino, a lo sumo, por su iniciativa. De allí que la legislación española, concretamente el Estatuto de los Trabajadores, no las denomina despido sino extinción del contrato por causas objetivas.

El despido individual puede tener dos tipos de causas: disciplinarias o de conducta (falta grave) y personales o de capacidad.

El que algunas leyes como la peruana hayan prescindido de éstas últimas ha hecho nacer la falsa identidad entre causa justa y falta grave, inhibiendo la aptitud para describir y precisar otras

(27) "La terminación de la relación de trabajo por iniciativa del empleador..."; en "Derecho Laboral", Montevideo, T. XXV, No 128, pp. 715. 716. 
causas posibles y válidas de terminación del contrato de trabajo por razones de tipo individual que no constituyan falta grave.

Se deben contemplar necesariamente otras causas de terminación del vínculo laboral que no mancillen ni agravien al trabajador, que no se originen en dolo o culpa de éste, pero que sean justificatorias de la terminación del contrato, no como sanción ni por vía disciplinaria, pero sí como reconocimiento de una realidad social que el Derecho no puede ignorar.

El reciente Convenio $158^{\circ}$ de la OIT las denomina "causas justificadas relacionadas con la capacidad del trabajador"; o con la persona de éste, dice PLA, y "deben obstar al cumplimiento regular del contrato. Las expresiones utilizadas son varias: ineptitud, incapacidad, inhabilitación, imposibilidad de realización de las tareas, pérdida o reducción de eficiencia" (28).

En realidad, la falta de capacidad puede tener dos ángulos o perspectivas: personal, y funcional o formal.

Capacidad personal es sinónimo de idoneidad, de calificación: Una persona puede carecer de ella o, lo que es más comprensible, haberla perdido.

Dentro de este grupo de causales podrían comprenderse:

- La invalidez absoluta, causal obvia que la ley peruana insólitamente ignora, creando así un enorme vacío normativo.

- Invalidez parcial o pérdida de facultades específicas, como sería el caso de la artritis deformante en la mecanógrafa o el glaucoma en el chofer.

- Reducción de la eficacia, por causa de edad principalmente, situación que se presenta en el cirujano o el piloto de aviación, por ejemplo.

- La edad avanzada en sí misma, con todo lo que representa de pérdida de la capacidad laboral.

- La jubilación ordinaria o normal, cuando se ha alcanzado el tope máximo legalmente posible. Sin violentar el principio de vo-

(28) Ibíd, p. 716. 
luntariedad de este beneficio, cabe estudiar, sin embargo, el mejor derecho de una persona que recién acude al mercado laboral.

- La desadaptación "social", imposibilidad de relacionarse razonablemente con los compañeros de trabajo.

La enfermedad muy prolongada, contagiosa o repugnante, de que hablan algunas legislaciones.

- La falta de adaptación a nuevas condiciones técnicas y la imposibilidad real de un aprendizaje serio.

- La inhabilidad, desadaptación al puesto, ineptitud, sin connotaciones dolosas o culposas.

- La falta de capacidad funcional o formal es la pérdida de un requisito indispensable para ejercer un cargo o puesto.

Curiosamente, dada la falsa identidad entre causa justificada y falta grave en que incurre la ley peruana, y como excepción a ella, se contempla esta situación en el inc. i) del art. $4^{\circ}$ del D.L. 22126.

Art. $4^{\circ}$.- Inciso $i$ ): "igualmente es causal de despedida justificada la sanción de inhabilitación impuesta al trabajador por la Autoridad Administrativa o Judicial para el ejercicio de la actividad que desempeñe en el centro de trabajo, si lo es por tres meses consecutivos".

El adverbio "igualmente" denota asimilación, no identificación. Este inciso, que actúa de modo similar que los demás, no es igual a ellos porque se refiere a una situación ajena a la relación laboral, a algo sucedido fuera del entorno del contrato de trabajo, aunque indirectamente se refiera a él para impedir su ejecución.

¿A qué situaciones se refiere este inciso? Un análisis casuístico ayudará a la comprensión: al chofer que le requisan el brevete; al piloto que le suspenden la licencia; al abogado, al médico, al profesional en general cuya patente es retenida, impidiéndole desempeñar su profesión u oficio. Si dicha profesión u oficio es determinante en la ocupación del trabajador y la inhabilitación impide su ejercicio, se autoriza la rescición del contrato por imposibilidad de cumplimiento.

Pero, y aquí está lo importante, la infracción que determinó la sanción judicial o administrativa debe haber sido cometida ex- 
tra-laboralmente, ser ajena a la relación de trabajo. Si perteneciera a ésta configuraría otra falta. Al no referirse a la relación, no es falta grave laboral, aunque su efecto fundamental se le asimile.

\section{Falta Grave y Estabilidad Laboral. Los Efectos de la Falta Grave}

El efecto más importante y universal de la falta grave es autorizar el despido. El despido disciplinario o punitivo está contemplado en todas las legislaciones: lo contrario sería un despropósito, pues implicaría virtual impunidad para la comisión de faltas graves.

La ruptura del vínculo laboral es la sanción capital, por lo que se reserva para la infracción más grave. Este efecto es fundamental en legislaciones que, como la peruana, consagran la estabilidad absoluta como derecho del trabajador a no ser despedido sin justa causa, contemplada en la ley y debidamente comprobada.

Para BARASSI, el despido debe reunir tres requisitos fundamentales: justa causa, culpa grave por parte del trabajador, y que la valorización de la misma sea hecha, no con criterio absoluto, sino teniendo en cuenta "el medio ambiente en que se efectiviza el trabajo" (29).

CARRO ZUÑIGA considera que son muchos los factores objetivos y subjetivos que juegan rol importante en la calificación, y que entre ellos debe atenderse: "El tipo de contrato de trabajo, la índole del cargo; la jerarquia, el deber del empleado; la especialidad laboral, el uso de ciertas clases de materias primas; el grado de confianza, orden y moralidad, y las razones de disciplina y obediencia que demandan las funciones; el acatamiento a disposiciones legales inherentes a éstas; el riesgo en potencia -no necesariamente efectivo - que pueda llegar a lesionar el prestigio, la seriedad o la solvencia moral de la empresa, para no citar el económico; la antigüedad en la prestación de los servicios; los antecedentes disciplinarios del empleado, etc. (30).

(29) Cit. por MARC, Op. cit., p. 324.

(30) Op. cit., p. 300. 
Esta enumeración pone de relieve un hecho fundamental: el despido no es un acto automático o mecánico sino deliberado, voluntario; consiste en una decisión expresa del empleador, adoptada en base al análisis del caso y a sus múltiples implicancias.

Lo importante es, de otro lado, como dice SAGARDOY, que el despido por falta grave "se deberá limitar a aquellos casos en que no esté justificada otra conducta distinta del empleador" (31).

Otro efecto de la falta grave es autorizar que el cese se produzca en forma intempestiva o inmediata, vale decir, sin preaviso.

Aún las legislaciones que no prohiben la capacidad de despido sin causa sino que sólo la limitan al requisito de un preaviso, conceden la posibilidad de prescindir de éste ante la comisión de falta grave.

Este efecto es de obvia justificación: No puede prolongarse la pemanencia de quien por sus propios actos está determinando la ruptura del vínculo, actos que, por cierto, son de suyo de tal naturaleza que, como dice la legislación italiana, no consienten la continuación, ni aún provisional, de la relación. cios.

Finalmente, la falta grave genera la pérdida de ciertos benefi-

En primer lugar, de la indemnización por despido incausado, que es, la mayoría de las veces, un requisito alterno, sustitutorio del preaviso.

En algunas legislaciones ésta pérdida puede extenderse a otros beneficios sociales como compensación por tiempo de servicios, vacaciones devengadas, indemnizaciones especiales acordadas a mujeres y menores, o por embarazo, etc.

\section{La Falta Grave en la Ley Peruana}

a) Del Código de Comercio a la estabilidad laboral

La falta grave laboral tiene en nuestro país antigua data.

(31) Op. cit. p. 21 
Contrariamente a lo que pudiera pensarse, no aparece como correlato de la estabilidad laboral, con el Decreto Ley 18471 en 1970 , sino que fue introducida y sancionada por el Código de Comercio promulgado en 1902, lo que revela, de paso, que su existencia conceptual es anterior.

No hay, sin embargo, paralelo alguno entre la realidad laboral que regia el Código de Comercio y las normas modernas. El solo hecho de ser un Código para regular la actividad comercial es revelador de la evidente diferencia: legislaba en atención a la personalidad del empleador, del comerciante, en tanto que el derecho laboral es un derecho de la clase trabajadora.

No se ligaba entonces a una idea de estabilidad laboral, sencillamente porque tal idea no existía. Ni existió en nuestro país sino hasta su abrupta aparición con el ya citado D.L. 18471, salvo la protección que la ley daba al empleado con inminentes expectativas jubilatorias.

¿Cuál era la función de la falta grave en el Código de Comercio? Operativamente, actuaba igual que hoy como justificatoria del despido intempestivo, sin aviso. Aunque, por cierto, el patrono no estaba impedido de despedir sin expresión de causa; por el contrario, estaba autorizado a ello con el simple requisito del preaviso de 90 dias o el pago de una indemnización equivalente ( 3 sueldos), en el caso de empleados; y sin preaviso ni indemnización alguna, en el caso de obreros.

La invocación de la falta grave exoneraba al empleador de ese requisito alternativo, pero $-\mathrm{y}$ esto era lo sustancial, lo verdaderamente importante - acarreaba la pérdida de los llamados beneficios sociales: compensación por tiempo de servicios, indemnización por vacación no gozada, etc. Este efecto quedó suprimido con la dación del D.L. 21116.

Es útil esta retrospección para poder comparar someramente y compulsar la magnitud del cambio producido, ángulo sobre el que volveremos más adelante.

La tipificación de la falta grave en el Código de Comercio era simple en el enunciado, breve en la enumeración (sólo 3 faltas 
expresas) y amplia en su aplicación. Esto último por haber dado la Ley No. 4916 (art. $2^{\circ}$ ) al juez la facultad de interpretar por vía analógica e incorporar nuevas infraccionès de génesis jurisprudencial, tratándose de situaciones cuya naturaleza grave las hiciera asimilables a las expresamente contempladas en la ley.

Apreciamos aquí otro cambio sustantivo: Las normas que regulan la falta grave en relación con la estabilidad -DD.LL. 18471 y 22126 - son rígidas en la tipificación, que responde al principio penal "nullum crime sine lege".

El art. $294^{\circ}$ del Código de Comercio decía: "Serán causas especiales" para que los comerciantes puedan despedir a sus dependientes, no obstante no haber cumplido el plazo de empeño:

1) El fraude o abuso de confianza en las gestiones que les hubiere confiado.

2) Hacer alguna negociación de comercio por cuenta propia, sin conocimiento expreso y licencia del principal.

3) Faltar gravemente al respeto y consideración debidos a éste o a las personas de su familia o dependencia."

A ellas se añadió posteriormente el abandono de trabajo (ausencia injustificada por más de 3 días consecutivos: D.S. de 4.6. 51 ) y la impuntualidad reiterada.

¿Dónde encontrar las principales diferencias entre el régimen anterior al D.L. 18471 y el que nos rige, con las variaciones introducidas por el D.L. 22126, a partir de aquél? El cuadro siguiente ayudará a visualizar esas diferencias.

El cuadro que antecede sólo persigue señalar algunas, las mas importantes diferencias entre los regímenes que se han sucedido en nuestra evolución laboral. Requiere para su desarrollo general explicaciones que exceden los límites de este trabajo. Aún así, es útil para apreciar la evolución producida.

b) Del D.L. 18471 al D.L. 22126

Antes de examinar al detalle el art. $4^{\circ}$ del D.L. 22126 , que hoy nos rige, interesa una vez más una comparación evolutiva; en este caso, concretamente en lo que va del D.L. 18471 al 22126. 


\begin{tabular}{|c|c|c|c|c|c|}
\hline & & \multirow{2}{*}{$\begin{array}{l}\text { C. de Comerclo } \\
\text { Ley } 4916 / 8439\end{array}$} & \multirow{2}{*}{$\begin{array}{l}\text { D.L. } 18471 \\
3 \text { meses o mas }\end{array}$} & \multicolumn{2}{|c|}{ D. L. 22126} \\
\hline & & & & $\begin{array}{l}3 \text { meses a } \\
3 \text { añas }\end{array}$ & 3 anos o más \\
\hline \multirow[t]{5}{*}{ Empleados } & $\begin{array}{l}\text { Preaviso, sin expresión } \\
\text { de causa. }\end{array}$ & 3 meses & NO & 3 meses & NO \\
\hline & $\begin{array}{l}\text { Indemnización (alternativa } \\
\text { a preaviso, a decisión del } \\
\text { e mpleador) }\end{array}$ & 3 sueldos & No & 3 sueldos & No \\
\hline & Reponición & NO & SI & No & SI \\
\hline & $\begin{array}{l}\text { Indemnización (alternativa } \\
\text { a reponición, a decisión del } \\
\text { trabajador) }\end{array}$ & No & 3 sueldos & NO & $\begin{array}{l}12 \text { sueldos } \\
\text { (con tope) }\end{array}$ \\
\hline & $\begin{array}{l}\text { Pérdida de beneficios (por } \\
\text { falta grave) }\end{array}$ & SI & $\begin{array}{l}\text { No, desde } \\
\text { el D.L. } \\
22116\end{array}$ & $\begin{array}{l}\text { No, desde } \\
\text { el D.L. } \\
22116\end{array}$ & $\begin{array}{l}\text { No, desde } \\
\text { el D.L. } \\
22116\end{array}$ \\
\hline
\end{tabular}

\begin{tabular}{|c|c|c|c|c|c|}
\hline & & \multirow{2}{*}{$\begin{array}{l}\text { C. de Comercio } \\
\text { Ley } 4916 / 8439\end{array}$} & \multirow{2}{*}{$\begin{array}{l}\text { D.L. } 18471 \\
3 \text { meses o más }\end{array}$} & \multicolumn{2}{|c|}{ D. L. 22126} \\
\hline & $\because$ & & & $\begin{array}{l}3 \text { meses a } \\
3 \text { ahos }\end{array}$ & 3 años o más \\
\hline \multirow[t]{5}{*}{ Obreros } & $\begin{array}{l}\text { Preaviso, sin expresión } \\
\text { de causa. }\end{array}$ & No & No & 3 meses & No \\
\hline & $\begin{array}{l}\text { In demnización (alternativa a } \\
\text { preaviso, a decisión del } \\
\text { empleador) }\end{array}$ & No & NO & 3 sueldos & NO \\
\hline & Reposición & No & SI & No & SI \\
\hline & $\begin{array}{l}\text { Indemnización (alternativa a } \\
\text { reposición, a decisión del } \\
\text { trabajador) }\end{array}$ & NO & 3 sueldos & NO & $\begin{array}{l}12 \text { sueldos } \\
\text { (con tope) }\end{array}$ \\
\hline & $\begin{array}{l}\text { Pérdida de beneficios (por } \\
\text { falta grave) }\end{array}$ & SI & $\begin{array}{l}\text { No, desde } \\
\text { el D.L. } \\
21116\end{array}$ & $\begin{array}{l}\text { No, desde } \\
\text { el D.L. } \\
21116\end{array}$ & $\begin{array}{l}\text { No, desde } \\
\text { el D.L. } \\
21116\end{array}$ \\
\hline
\end{tabular}


En primer lugar, el D.L. 22126 amplía las causales, considera faltas que el anterior no contemplaba. En tal sentido es una norma más flexible y realista, pues el D.L. 18471 adoleció precisamente de lo contrario. Discriminando una a una las faltas enumeradas, puede decirse que el D.L. 18471 señalaba 9 faltas que, en realidad, eran más pues algunas de ellas son susceptibles de subdivisión: por ejemplo, utilización y disposición de los bienes son conceptos distintos, que la ley asimila entre sí. El D.L. 22126 amplia el número a por lo menos 12 (subdividibles también algunas de ellas).

En segundo lugar. una curiosidad: No obstante lo dicho en el párrafo anterior, el número de incisos contenidos en los artículos equivalentes de los dos decretos es igual; se tipifican en la norma actual más faltas, pero en el mismo número de incisos. ¿Cuál es la explicación?: Muy sencilla. Los que antes eran incisos autónomos han sido convertidos en simples párrafos en la ley posterior; muchos incisos de ésta subsumen, involucran varios incisos de la anterior.

Esta fue una manera - más ingeniosa que jurídica- de dar la impresión que no se estaba ampliando el número de faltas, y no provocar un rechazo automático de parte de los trabajadores.

Lo cierto es que, más allá de sutilezas legislativas, el D.L. 22126 abrió la gama de faltas, incorporando algunas que no lo eran anteriormente, como es el caso del acto de violencia o la grave indisciplina que absurdamente la norma derogada ignoraba.

Aún asi, se quedó corto. Primero, por haber omitido la tipificación de infracciones importantes, y segundo, por haber mantenido la falsa identidad entre falta grave y causa justa.

El cuadro siguiente puede ser explicativo del cambio productivo:
D.L. 22126
D.L. 18471

Norma actual

Art. $4^{\circ}$ : Constituyen faltas gra-
Norma equivalente Art. $2^{\circ}$ : Constituye falta frave 
ves que dan lugar a la despedida justificada e inmediata del trabajador, las siguientes:

Inc.a(1) $\mathrm{E}$ l incumplimiento injustificado de las obligaciones.
Inc. a(2) La reiterada resistencia a las órdenes de sus superiores relacionadas con sus labores.
Inc. f) La reiterada resistencia a cumplir las órdenes de sus superiores en relación con sus labores.

Inc. b) La disminución deliberada y reiterada en el rendimiento de su labor, sea del volumen $y / o$ calidad de producción, salvo los casos no atribuibles al trabajador, tales como falta de insumos, obsolencia de maquinaria, mala calidad de la materia prima y otros análogos; No será exigible el requisito de la reinterancia cuando se trate de una decisión colectiva, en cuyo caso el 
ejercicio de licencia representativa no impedirá la aplicación de esta causal;

Inc. c) La utilización o disposición de los bienes del centro de trabajo o de los que se encuentren bajo su custodia, en perjuicio del empleador y en beneficio propio o de terceros.

Inc.d(1) El uso o entrega a terceros de procedimientos de fabricación considerados secretos, así como informaciones de igual naturale$\mathrm{za}$;

Inc.d(2) La realización de actividades idénticas a las que ejecuta para el empleador atrayéndose la clientela sin su autorización escrita.

Inc.d(3) Proporcionar intensionalmente información falsa al empleador causándole perjuicio.
Inc. c) La utilización o disposición de los bienes del centro de trabajo en perjuicio del empleador $y$ en beneficio propio o de terceros.

Inc. e) El uso o entrega a terceros de procedimientos de fabricación considerados secretos, así como informaciones de igual naturale$\mathrm{za}$, que ocasione perjuicio al empleador.

Inc. d) La realización en provecho propio o de terceros de actividades idénticas a las que ejecuta para el empleador, atrayendo la clientela de éste, causándole grave perjuicio.

Inc. b) Las informaciones falsas proporcionadas intencionalmente al empleador, o sus superiores que ocasionen perjuicios graves a la empresa. 
Inc. e) La concurrencia reiterada al trabajo en estado de embriaguez o bajo la influencia de drogas $o$ sustancias estupefacientes y aunque no sea reiterada. cuando por la naturaleza de la función o del trato que desempeña revista $2 x c^{\wedge}$ pcional gravedad.

La Autoridad Policial prestará su concurso para coadyuvar en la verificación de tales hechos lo que hará constar en el atestado respectivo. La negativa del trabajador a someterse a la prueba correspondiente se considerará como reconocimiento.

Inc. f) Las ausencias injustificadas por más de tres días consecutivos.

Inc.f (2) Las ausencias injustificadas no consecutivas por más de cinco días en un período de treinta dias calendarios.

Inc.f(3) Más de quince dias en un período de ciento ochenta dias calendario.
Inc. g) La concurrencia reiterada al trabajo en estado de embriaguez o bajo la influencia de narcóticos, y aunque no sea reiterada. cuando por la naturaleza de la función o del trabajo revista excepcional gravedad.
Inc. h) Las ausencias injusti- ficadas por más de tres días consecutivos; e

Inc.i (1) Ausencias injustificadas por más de cinco dias al mes.
Inc.i (2) Ausencias injustificadas por más de 15 días al semestre. 
Inc.g El incurrir en acto do violencia. en grave in. displina o en reiter. do faltamiento de palabra en agravio del empleador, de sus representantes, del personal jerárquico o de sus compañeros de labor, dentro del centro de trabajo o fuera de él. en este último caso siempre y cuando los hechos se deriven directamente de la relación laboral:

Inc. h) El causar intencionalmente daños materiales en los edificios, instalaciones, obras, maquinarias, instrumentos. documentación, materias primas y demás bienes, de propiedad de la empresa o en posesión de ésta; e.

Inc. i) Jgualmente es causal de despedida justificada la sanción de inhabilitación impuesta al trabajador por la Autoridad Judicial para el ejercicio de la actividad que desempene en el centro de trabajo, si lo es por tres meses consecutivos. 
c) La falta grave en el D. L. 22126

Contempla el D.L. 22126, en los nueve incisos de su art. $4^{\circ}, 14$ faltas y una causal de despido que no constituye falta laboral.

Inc. a) "El incumplimiento injustificado de las obligaciones, la reiterada resistencia a las órdenes de sus superiores relacionadas con sus labores y la inobservancia del Reglamento Interno de Trabajo y de Seguridad Industrial, debidamente aprobado por la Autoridad Administrativa de Trabajo, que ocasionen daño o perjuicio, o creen riesgo grave al empleador, a personas, bienes o a la seguridad del centro de trabajo".

En este inciso se reúnen, en realidad, tres faltas de naturaleza y contenido distintos.

a.1) La primera es el incumplimiento injustificado de obligaciones. Por la forma de construcción utilizada, debe entenderse que se complementa con el párrafo final del inciso; en consecuencia debe leerse: "El incumplimiento injustificado de las obligaciones que ocasione daño o perjuicio o cree riesgo grave al empleador, a personal, a bienes o a la seguridad del centro de trabajo".

Ello es así por el uso del verbo "ocasionar" en plural (en el texto legal), que obviamente lo refiere a las tres faltas contempladas en el inciso. Dentro de la especificidad de la ley, ésta es una falta muy genérica pues, de alguna manera, engloba a todas las demás. Por su naturaleza es, además, muy grave pues importa la violación de los deberes fundamentales del trabajador.

1.2) A la resistencia a cumplir las órdenes del empleador se la conoce como desacato o desobediencia; si es reiterada o contumaz, insubordinación.

Sobre su naturaleza, DE MEZQUITA la considera falta contra la disciplina, mientras MARC la reputa contraria a los deberes de subordinación jurídica o de colaboración jerárquica (33), lo que

(33) op. cit.,p. 318. 
concuerda mejor con la legislación en análisis, que coloca la indisciplina en otro inciso.

No es precisa la ley en cuanto al concepto de reiteración. En primer lugar, porque no se infiere el número de veces en que debe repetirse la infracción para que se considere reiterada. En segundo, porque no señala un término temporal. Finalmente, porque no indica si debe tratarse de órdenes distintas impartidas en diferente momento o si puede ser la misma orden repetida de inmediato, en forma sucesiva.

Puede suceder, por ejemplo, que se invoque una desobediencia cometida varios años atrás, como, inversamente, que se invoque la cometida minutos antes; esto, cuando a la negativa inicial sigue una nueva exigencia de cumplimiento de la misma orden.

a.3) La inobservancia del reglamento de trabajo y de seguridad industrial es falta sólo si el instrumento normativo se encuentra formalmente aprobado por la Autoridad Administrativa de Trabajo. Su gravedad depende del daño, perjuicio o riesgo creado al empleador, a personas, a bienes o a la seguridad del centro de trabajo.

No es, pues, cualquier infracción reglamentaria, sino sólo aquella que reviste particular importancia.

Debe repetirse, sin embargo, que la gravedad de la falta por sus efectos es factor común a los tres casos tipificados en el inciso a) y no sólo a este último, como parecería de una lectura superficial.

En conjunto, las tres faltas se refieren a las facultades privativas del empleador: normativa - plasmada en los reglamentos de trabajo y de seguridad; directriz- que se manifiesta a través de órdenes que deben ser cumplidas; y a la propia esencia contractual de la relación de trabajo - que se concreta en las obligaciones que el trabajador asume en cuanto tal.

Inciso b): "La disminución deliberada y reiterada en el rendimiento de su labor, sea del volumen y/o calidad de producción, salvo los casos no atribuibles al trabajador, talés como falta 
de insumos, obsolescencia de maquinaria. mala calidad de la materia prima 1 otros análogos,

Vo sera exigible el requisito de la reiterancia cuando se trate de una decisión colectiva, en culo caso el ejercicio de licencia represcntativa no impedirá la aplicación de esta causal".

Precepto de los más controvertidos del D.L. 22126, éste tiene por objeto prevenir el sabotaje velado a la producción que podría llevar a cabo. individual o particularmente, un trabajador. cuyas motivaciones no vienen al caso.

Es clara la exigencia de que la disminución en el rendimiento laboral sea reiterada, aunque más preciso sería. quizás, decir continuada o frecuente; pero, sobre todo y fundamentalmente, deliberada, intencional, dolosa.

La disminución puede ser cuantitativa (volumen) o cualitativa, y salva los casos no atribuibles al trabajador: falta de insumos, obsolescencia de la maquinaria, mala calidad de la materia prima, etc.; salvedad innecesaria, por cierto, pues excluye la intencionalidad, pero útil para clarificar y precisar la intención legislativa.

En sentido estricto, esta falta individual o aislada resultaría comprendida en la primera parte del inciso a). El haberla separado le da vigor y precisión a la tipificación.

La verdadera envergadura del inciso aparece en su segunda parte, que elimina el requisito de la reiterancia (reiteración. más bien) cuando se trata de una decisión colectiva.

Algunos han querido encontrar en ello una limitación al derecho de huelga consagrado por la Constitución. No hay tal, sin embargo. La huelga es una abstención pacifica y voluntaria del trabajo que debe ser total $y$, por consiguiente, ejercerse fuera del puesto y del centro de trabajo.

El tortuguismo, el trabajo a ritmo lento, a desgano o a reglamento, los brazos caídos, son modalidades irregulares de acción directa que las legislaciones normalmente reprueban. 
La razón es simple para esta prohibición: La huelga es un arma de los trabajadores frente al patrono que implica una autolesión, un sacrificio; es un enfrentamiento abierto y leal, por el que se busca imponer condiciones a través de una coacción. que la ley legitima precisamente por esas características.

El sabotaje pasivo, en cambio, persigue provocar el daño al adversario sin correr riesgos ni asumir responsabilidades ni sufrir privaciones. Quien trabaja a desgano, quien boicotea la produción, simula trabajar pero en realidad no lo hace; su acto de presencia es puramente formal; no hay prestación porque el trabajo, para ser tal, debe prestarse en las condiciones de calidad y cantidad comprometidas.

Quien así actúa pretende estar cumpliendo, para reclamar, en su momento, la remuneración correspondiente, remuneración que el que está en huelga real no percibe por razones obvias.

Hay, pues, en estas modalidades irregulares una deslealtad y una falsía que la ley no puede cohonestar; y por eso las prohibe.

Otro aspecto crítico es que no señala pauta alguna acerca de quién puede ser despedido. Ello abre paso a una discrecionalidad rayana en la arbitrariedad.

Pero sí está en caja la ley en no privilegiar o inmunizar al dirigente sindical que, por estar de licencia, aparentemente no sería partícipe de la acción.

El inciso b) del art. $4^{\circ}$ debe ser examinado, procesalmente, en concordancia con el art. $8^{\circ}$.

A diferencia de todas las demás faltas - todas ellas de naturaleza estrictamente individual, que autorizan la ejecución del despido a la sola decisión del patrono-, en ésta, de contenido colectivo, se le impone un trámite previo.

De acuerdo a lo dispuesto en el art. $8^{\circ}$ del D.L. 22126, el empleador no puede despedir al trabajador que comete la falta tipificada en la segunda parte de este inciso, en tanto no se expida por la Autoridad Administrativa de Trabajo la resolución autorita- 
tiva que declare fundada la petición del empleador. Este trámite previo ha tenido la virtud de evitar excesos en la aplicación de esta sanción, pero por otro lado, ha constituido prácticamente una barrera infranqueable para su utilización, pues hasta el momento no se conocen o son poquísimas las resoluciones de la Autoridad de Trabajo que autoricen dichos despidos.

Inciso c) "La utilización o disposición de los bienes del centro de trabajo o de los que se encuentren bajo su custodia, en perjuicio del empleador y en beneficio propio o de terceros".

Robo, apropiación ilícita, uso indebido, todo ello aparece envuelto en las expresiones "utilización o disposición de los bienes, en beneficio propio o de terceros".

Sobre la justificación de la norma no es necesario casi hablar: es obvia.

Los bienes pueden pertenecer al empleador o estar bajo su custodia. Se refiere esto último fundamentalmente a dos situaciones: bienes de clientes o proveedores, y bienes de los propios trabajadores, dado que el empleador tiene, entre sus obligaciones, el deber de vigilancia de los mismos.

La ley no señala cuantía. Hace bien. La jurisprudencia ha sido, hasta ahora, estricta en la sanción.

Ello también influye en la exigencia del perjuicio al ẹmpleador, que puede ser económico o material, pero también moral y disciplinario: Un robo tolerado por su baja cuantía puede ser estimulante para otros futuros.

El uso indebido es falta normalmente menor. Aquí sí debe estar presente y de modo claro el perjuicio al patrono: si no lo hubiere, debe ser sancionado con menor dureza.

Inciso d): "El uso o entrega a terceros de procedimientos de fabricación considerados secretos, asi como informaciones de igual naturaleza: la realización de actividades idénticas a las que ejecuta para el empleador, atrayéndose la clientela sin su autoriza- 
ción escrita, o proporcionar intencionalmente información falsa al empleador causándole perjuicio".

d.1) La infidencia o, más punible aún, el espionaje industrial constituyen faltas de inocultable gravedad. El D.L. 18471 anterior al actual la tipificaba bajo la exigencia de que causara perjuicio. En nuestra opinión, aunque con redacción anfibológica, la norma vigente también lo exige, pues el inciso es uno solo y, aunque hay mal uso de las comas, la condición parece obvia.

d.2) La competencia o concurrencia desleal es también falta injustificable.

Atraer la clientela del patrono ofreciendo o dando servicios o bienes idénticos es, ética y legalmente, una seria infracción.

Son proclives a ella algunos trabajadores que, aprovechando la difícil fiscalización de actos realizados fuera del centro laboral, pueden promover ventas ajenas. También lo son los operarios de algunos servicios, que ofrecen los propios a un costo inferior al de los precios que cobra su empleador.

Resulta curiosa pero posiblemente necesaria la exigencia de que la autorización sea escrita. Ello coloca la carga de la prueba del lado del presunto infractor, lo que no significa presumir la culpabilidad dado que, antes que él deba demostrar nada, el patrono deberá alegar y probar la competencia desleal, por lo que aquélla actúa de contraprueba.

d.3) No es fácil encontrar casuística sobre informaciones falsas. Algunas la aplican, por ejemplo, a los datos proporcionados en la solicitud de ingreso que, siendo declaración jurada, podrían inducir a un injustificado buen concepto sobre el postulante y determinar su contratación.

Al respecto CABANELLAS señala que "el hecho de que el trabajador, en el momento de celebración del contrato, induzca a error al patrono, dando equívocas referencias o haciendo falsas declaraciones, o pretendiendo, por ejemplo, poseer cualidades o llenar las condiciones que constituyen unos de los puntos esenciales del contrato, en caso de descubrirse aquellas, o de no poseer o no 
llenar éstas, constituye causa de justo despido. Este motivo deriva de la ineptitud del trabajador para la tarea pactada; pero si por parte del trabajador hubiera habido dolo para lograr el consenso del patrono, más que encontrarnos con una causa de despido, estaríamos frente a la nulidad del contrato por vicio del consentimiento" (34).

Otros consideran, por ejemplo, que la comete quien afirma estar cumpliendo una labor aunque no la esté realizando (caso del visitador médico que no cumple con el rol de visitas establecido) o quien se reporta enfermo o quien informa haber concurrido a atención clínica, no obstante gozar de perfecta salud.

Lo cierto es que se presta para variadas interpretaciones, a la vez que muchas de las situaciones invocadas a su amparo podrían resultar tipificadas en otros incisos.

En lo que sí hay que reparar es en la exigencia del perjuicio. cuya aplicación expresa a esta falta es semánticamente inequivoca. No obstante, debe tenerse presente lo afirmado por SAGARDOY cuando sostiene que "es preciso acudir a la presunción, con carácter de juristantum, de modo que el hecho de trabajar en actividad análoga o idéntica a la de la empresa principal, presupone un perjuicio para la misma" (*).

Inciso e): "La concurrencia reiterada al trabajo en estado de embriaguez o bajo la influencia de drogas o sustancias estupefacientes y aunque no sea reiterada, cuando por la naturaleza de la función o del trabajo que desempeña revista excepcional gravedad.

La Autoridad Policial prestará su concurso para coadyuvar en la verificación de tales hechos, lo que hará constar en el atestado respectivo.

(34) CABANELlaS, cit. por Jorge Ortega Torres: Código Sustantivo del Trabajo y Código Procesal del Trabajo de Colombia concordando y comentado, Bogotá, Ed. Flores, 1972, p. 136. 
La negativa del trabajador a someterse a la prueba correspondiente se considerará como reconocimiento.

E1 D.L. 18471 hacía referencia a "narcóticos". Más preciso y actual, el D.L. 22126 habla de "drogas o sustancias estupefacientes".

Se exige la reiteración. No se indica qué se entiende por tal concepto, vaguedad que la jurisprudencia debe precisar casuísticamente. Una vez más habría sido preferible otra expresión como "frecuente o constante".

No se señala tampoco un grado para la embriaguez, que es susceptible de medición a través del llamado "dosaje etílico" (proporción del alcohol en la sangre). Tendría que recurrirse al concepto médico de embriaguez, que generalmente está referido a la pérdida de aptitud o habilidad para la conducción de un vehículo.

Precisamente al caso de los conductores se refiere, casi directamente, la parte del inciso que prescinde del requisito de la reiteración cuando, por la naturaleza de la función o del trabajo, el estado de inecuanimidad adquiera esencial gravedad. Es indudable que para el chofer de un autobús, de cuyo control depende la vida de decenas de pasajeros, transeúntes y otros conductores, y la integridad del vehículo y otros bienes. la embriaguez o el uso de drogas es falta gravísima desde la primera vez que se comete. No es necesario esperar a su repetición. En tal sentido dice bien José SERRANO CARVAJAL cuando afirma que "...la regla general de la gravedad del incumplimiento en el caso de la embriaguez no tiene porqué centrarse sólo sobre la habitualidad, sino que, en muchos casos, viene agravada por circunstancias que hacen de justificante del despido" (35). Por lo demás, si ubicamos la embriaguez como integrante de lo que ALONSO OLEA califica como "deber genérico de buena conducta". debemos admitir con el mismo SERRANO que "....está en las características de cada contrato de trabajo la medida en que la inobservancia de lo dispuesto de modo general en las normas sean causas justas de despido" (36).

(35) El despido: la embriaguez y falta de aseo, en Dieciséis lecciones sobre causas de despido, Madrid, Universidad de Madrid, 1969, p. 196.

(36) Cf. José SERRANO CARBAJAL, Op. cit., p. 195. 
La intervención de la autoridad policial está justificada por ser ella la llamada, normalmente, a verificar el mal estado, máxime si es en las dependencias policiales donde se practica el dosaje.

Se ha criticado el acápite final, pero parece necesario. Sucede que muchas veces la persona, víctima ella misma de su descontrol, opone resistencia al examen. Es prudente, entonces, no forzarla sino dar valor de evidencia a la propia negativa. Lo contrario sería convalidar la frustración de la prueba por acto propio y en el propio provecho.

Inciso f): "Las ausencias injustificadas por más de tres dias consecutivos o las ausencias injustificadas no consecutivas por más de cinco días en un periodo de treinta días calendarios o más de quince dias en un periodo de ciento ochenta días calendario".

f.1.) Es el abandono de trabajo. Sobre su naturaleza y justificación no es necesario abundar. Quien deja de concurrir a sus labores por un lapso continuo está demostrando con hechos su desapego a las mismas, su voluntad tácita de incumplirlas, de romper el contrato.

No autorizar al patrono a despedir sería lo mismo que equiparar el retiro voluntario al abandono o dejación intempestiva del puesto. Ninguna ventaja tendría quien se ajusta a la ley frente a quien la viola.

Más de tres días consecutivos es, por lo demás, un término ya profundamente enraizado en la práctica laboral peruana, desde siempre.

f.2.) Las ausencias no consecutivas por más de 5 dias en un mes fueron, como falta grave, una novedad del D.L. 18471.

Antes; el D.S. de 4 de junio de 1951 la había contemplado pero con carácter restringido (justificando el despido sin indemnización pero no la pérdida de beneficios, por lo que eran una falta grave menos grave que las demás) y sin la precisión matemática de la norma actual.

El D.L. 22126 mejora al 18471 al indicar "un perfodo de 30 
días calendarios" en vez de "mes", como anteriormente decía, racionalizando el cómputo al señalar un período que equivale a un mes, pero no lo es en estricto sentido, infiriéndose que se computa desde la fecha de la primera inasistencia.

f.3.) Lo dicho en el punto anterior es exactamente aplicable al caso semestral. El D.L. 18471 decía imprecisamente "más de 15 días al semestre". El D.L. 22126 dice "en un período de 180 días calendario".

Inciso g): "Incurrir en acto de violencia, en grave indisciplina o en reiterado faltamiento de palabra en agravio del empleador, de sus representantes, del personal jerárquico o de sus compañeros de labor, dentro del centro de trabajo o fuera de él, en este último caso siempre y cuando los hechos se deriven directamente de la relación laboral".

La violencia no tiene que ser grave, basta con que sea violencia. La indisciplina sí debe serlo. El faltamiento de palabra debe ser reiterado, lo que no se exige en los casos anteriores.

GARCIA MARTINEZ comenta sobre el tema: "Siempre hay que tener presente que, cuando se trata de indisciplina o insubordinación, más que el daño material que el hecho haya podido ocasionar al negocio, debe prevalecer el pacto moral, porque los actos de esta naturaleza, cuando adquieren gravedad, atentan contra las bases fundamentales de toda organización comercial $o$ industrial" (37).

El agraviado con cualquiera de estos hechos puede ser el empleador, sus representantes, el personal jerárquico o los compañeros de labor. La falta es igual quienquiera sea el perjudicado.

Hasta aquí no cabe discusión. La falta es clamorosa en todas sus manifestaciones. Clamorosa fué, por ello, la gruesa omisión en que incurrió el D.L. 18471 peruano, que no contempló ningu-

(37) GARCIA MARTINEZ, cit. por Jorge Ortega Torres: Código Sustantivo del Trabajo, y Código Procesal del Trabajo de Colombia concordado y comentado, Bogotá, Ed. Temis, 1942, p. 136. 
na de estas infracciones. Crasa ignorancia de la naturaleza del contrato de trabajo, que impone no sólo obligaciones materiales sino. en su dimensión ética, respeto. consideración, lealtad. fïdelidad. valores cuyo quebrantamiento es tan grave o más aún que el simple descuido u omisión que aquella norma sí sancionaba.

Este contenido ético no queda circunscrito dentro de las paredes del taller ni limitado por las ocho horas de la jornada: las trasciende en el tiempo y en el espacio. De allí que la falta existe aunque se cometa fuera - temporal o espacialmente-- del centro de trabajo y a condición que los hechos deriven directamente de la relación laboral. Lo contrario habria dado margen a que los incidentes pudieran ser provocados deliberadamente en un lugar o en una hora ajenos a los de la labor, con impunidad.

Inciso hl: "El causar intencionalmente daños materiales en los edificios, instalaciones, obras, maquinarias, instrumento, documentación, materias primas y' demás bienes de propiedad de la Empresa o en posesión de ésta".

Este es el sabotaje, falta de las más graves que es posible concebir. La destrucción del centro de trabajo o de lo que en él es necesario para la producción, constituye no sólo una falta laboral, sino - como en muchos otros casos - un delito.

Curiosa o sintomáticamente, el D.L. 18471 peruano no lo contemplaba ni sancionaba. Algún suspicaz podria pensar que fue una omisión deliberada.

\section{Las faltas omitidas}

Pese a que el D.L. 22126 representó en el Perú un considerable avance sobre su predecesor, el D.L. 18471. y aún admitiendo que la enumeración de faltas que aquél consigna es amplia y casi exhaustiva, aún así se ha incurrido en algunas omisiones.

\section{- Faltas de puntualidad}

La impuntualidad es distinta de la inasistencia y menos grave, pero su reiteración puede convertirla en un hábito nocivo. 
No basta para combatirla el no remunerar el tiempo no laborado efectivamente, porque la proporción salarial de unos pocos minutos diarios no surte ningún efecto ejemplarizador.

Puede el empleador, por cierto, transformar una tardanza en ausencia si, vencido un periodo de prudencial tolerancia, deniega el ingreso al servidor. Pero la medida peca por exceso y perjudica la producción.

La ley peruana tiene un correctivo muy eficaz, aunque quizás demasiado drástico: Para los obreros la remuneración del día de descanso semanal, llamada "salario dominical", está condicionada al requisito de asistencia y puntualidad en la respectiva semana; la ausencia y aún el simple retardo determinan su no percepción.

El obrero, entonces, "pierde" con su impuntualidad la retribución de un día completo, lo que es decisivo para estimular su presencia oportuna, temprana. No sucede igual con el empleado, cuyo haber mensualizado no está sujeto a condicionamientos de ese tipo; la impuntualidad en este sector es enormemente alta.

No cabe duda que al ser una tardanza menos grave que una ausencia, para que la acumulación de aquéllas pudiera justificar un despido se requeriría de un número considerablemente alto, capaz de demostrar la existencia de un vicio o hábito pernicioso.

\section{- Inasistencias reiteradas o sistemáticas}

La ley peruana contiène una evaluación cuantitativa de las ausencias: más de tres consecutivas, o más de cinco en un lapso de 30 días, o más de 15 en un lapso de 180 días.

Hay ausencias, sin embargo, que tienen valor cualitativo: las subsecuentes al descanso semanal o a los días festivos o a las vacaciones anuales.

La repetición de ausencias de ese tipo, reveladora de una conducta sistemática, debiera permitir la sanción aunque no se alcanzara el número exigido cuantitativamente. 
El camino es indirecto u oblícuo. Preferible es una norma explícita, que no sólo haga posible el despido sino que revele un respaldo social y moral para el mismo.

Debe mantenerse el principio de que la prisión provisional o preventiva, en cambio, no es suficiente en tanto no haya condena, pues al encausado se le presume inocente hasta que la sentencia sancione lo contrario. Tal coyuntura a lo que debe conducir es a una suspensión temporal del contrato, como dispone el artículo 45.1 del Estatuto de los Trabajadores español.

\section{- Inmoralidad}

La conducta deshonrosa, reñida con las normas éticas o de convivencia social; los actos deshonestos, que atentan contra la moral, o las buenas costumbres; las prácticas indecentes o indecorosas o bochornosas; son expresiones de inmoralidad que pueden dañar irreparablemente las relaciones humanas que rigen un contrato de trabajo.

Es más: Resultan lesivas a las relaciones horizontales del trabajador y sus compañeros de trabajo, pues rara vez o nunca consisten en un hecho aislado o circunstancial y sí, por el contrario, un comportamiento habitual.

No es necesario abundar en ejemplos, pero sí señalar, con SAAVEDRA ACEVEDO, que "para que se dé la falta grave de respeto por realizar actos contrarios a la moral, es necesario que haya conexión entre el acto y la situación laboral, sea por el lugar o por las personas" (38).

Finalmente, es necesario recalcar que la omisión en la tipificación de esta falta grave dio pábulo a que en cierta ocasión. en el Perú, se anulara el despido de un trabajador que fue sorprendido en prácticas homosexuales con un cliente en el lugar de trabajo y' dentro de la jornada de labor. Ese es el riesgo de la tipificación taxativa y ése el efecto de una omisión.

(38) SAAVEDRA ACEVEDO, Op. cit, p. 108. 
El profesor DEL PESO Y CALVO afirma que “...el porcentaje medido de faltas justificativas del despido supone (...) sometimiento a factores externos, sin valoración de cuánto de humano existe en el trabajador", concluyendo que "...la determinación a priori del número de faltas que deben exigirse para estimar como justa la sanción de despido (es) peligrosa" porque en unos casos las faltas, aún rebasando el número de las exigidas, pueden no alcanzar límite alto de gravedad, y en cambio, en otros casos, aunque las faltas son mínimas, por la forma en que se han cometido, pueden justificar el despido, lo que supervalora ese factor humano al que nos venimos refiriendo (39).

\section{- Condena Penal}

Debe tratarse de condena por actos ajenos o extraños a la relación laboral. Si derivaran de ésta, es obvio que, además del ilícito pasible penalmente, serían falta grave sancionable como tal directamente.

La condena debe, de otro lado, conllevar pena privativa de la libertad, por dos razones: porque tal pena está reservada a los delitos dolosos y porque la ejecución de la misma resulta incompatible con la prestación de los servicios.

Si la ejecución fuera suspendida, esto es, si la condena tuviera carácter condicional, ello sería revelador de que el delito no es socialmente peligroso. De otro lado, la propia suspensión haría viable la libre y normal concurrencia a las labores habituales.

Cabe advertir que en la práctica laboral peruana, la prisión definitiva es sancionada como abandono de trabajo; la ausencia forzosa por más de tres días es, en este caso, reputada como injustificada, por entenderse que lo que la motiva la explica pero no la justifica.

(39) Carlos DEL PESO Y CALVO, "Las faltas repetidas e injustificadas de puntualidad o de asistencia al trabajo como causa justa de despido", en Dieciséis lecciones sobre causas de despido, Madrid, Universidad de Madrid, 1969, pp. 62-63. 
Abuso de confianza es, en buena cuenta, la trasgresión de la buena fe contractual, el fraude, la deslealtad.

El contrato de trabajo, a más de las obligaciones objetivas de prestación del servicio, tiene un contenido ético que se expresa en los deberes de fidelidad y lealtad. Su quebrantamiento es falta, de cuya gravedad depende su sanción.

La trasgresión más frecuente a este respecto es la competencia o concurrencia desleal, la negociación por cuenta propia en perjuicio del empleador, pero no la única. Su importancia determina que se la tipifique expresamente. Pero el hacerlo asi, clarificando el concepto, trae como consecuencia que, dentro del sistema de falta tasada o limitativa, lo que constituye quebrantamiento de los deberes éticos no constituya falta grave por no estar explicitamente mencionada.

Fue la legislación española la que consagró el tríptico "fraude-deslealtad-abuso de confianza".

GONZALES ENCABO (40) considera que tales expresiones pudieran quedar reducidas "a la sola de deslealtad ... o, quizás, hubiera sido mejor, por contraposición a 'fidelidad', enunciar la 'infedelidad' como causa de despido".

\section{- Falsificación de documentos}

Preparar un documento falso o utilizarlo a sabiendas es no sólo ilícito laboral sino penal.

No obstante, es necesario tener presentes el motivo y la intención, así como la naturaleza del documento. Si lo que se persigue es una ventaja; si el documento es decisivo para la contratación o permanencia de la persona; si, en suma, la adulteración tiene caracteres serios y trascendentes, la falta es clarísima.

(40) Julián GONZALES ENCABO, "El fraude, la deslealtad o el abuso de confianza", en "Dieciséis lecciones sobre causa de despido", Madrid, 1969 , p. 135. 
Como infracción, podría estar comprendida en el concepto de "informaciones falsas": el documento apócrifo informa falsamente; pero en un sistema de rígida enumcración es preferible la tipificación directa y expresa.

No es posible agotar el repertorio de posibles faltas. Siempre habrá riesgo de omisión. Los criterios sociales y los principios morales no son tampoco inmutables, y deben soportar el embate del tiempo y las costumbres. 